\title{
Effects of exercise on biological trace element concentrations and selenoprotein $P$ expression in rats with fructose-induced glucose intolerance
}

\author{
Namika Miya, ${ }^{1,2}$ Asuka Uratani, ${ }^{2}$ Keita Chikamoto, ${ }^{3}$ Yuki Naito, ${ }^{1}$ Keiji Terao, ${ }^{3}$ Yutaka Yoshikawa ${ }^{2, *}$ \\ and Hiroyuki Yasui',* \\ 'Department of Analytical and Bioinorganic Chemistry, Division of Analytical and Physical Sciences, Kyoto Pharmaceutical University, \\ 5 Misasagi, Nakauchi-cho, Yamashina-ku, Kyoto 607-8414, Japan \\ ${ }^{2}$ Department of Health Sports and Nutrition, Faculty of Health and Welfare, Kobe Women's University, 4-7-2 Minatojima Nakamachi, Chuo-ku, Kobe, \\ Hyogo 650-0046, Japan \\ ${ }^{3}$ CycloChem Bio Co., Ltd., 7-4-5 Minatojima-minamimachi, Chuo-ku, Kobe, Hyogo 650-0047, Japan
}

(Received 9 October, 2019; Accepted 24 October, 2019; Published online 17 January, 2020)

In the present study, we investigated the effects of exercise intended to prevent or treat lifestyle-related diseases on the glucose tolerance, insulin level, lactic acid utilization, muscle glycogen synthesis, hepatic and renal oxidative stress, hepatic selenoprotein $P$ and biological trace element levels in organs of obese, glucose-intolerant rats. We fed normal, healthy rats a $20 \%$ casein diet while the glucose-intolerant, obese rats received a high-fructose diet. They were forced to run for one hour per day, six days per week, for ten weeks. Exercise reduced visceral fat and ameliorated glucose tolerance in the high-fructose group, lowered blood lactic acid levels, improved lactic acid usage efficiency, and increased oxidative stress and hepatic levels of $\mathrm{Mn}, \mathrm{Fe}, \mathrm{Cu}$, and $\mathrm{Zn}$ in the normal and high-fructose groups. Additionally, exercise significantly upregulated hepatic selenoprotein $P$ expression in both groups, however, its effect was remarkable in healthy group. On the other hand, muscle glycogen synthesis was not markedly enhanced in high-fructose-diet rats but in normaldiet rats in response to exercise. It is concluded that exercise conditions rather than exercise load must be customized and optimized for each health and disease states in advance before starting exercise training intended to prevent or treat lifestylerelated diseases.

Key Words: exercise effect, glucose intolerance, selenoprotein $\mathrm{P}$, biological trace elements

A bout $90-95 \%$ of all diabetes patients have the type 2 form. This condition is characterized by poor glucose intolerance and is associated with retinopathy, nephropathy, and neuropathy. Moreover, it increases the risks of stroke and ischemic heart disease and significantly reduces patient quality of life (QOL). Therefore, effective treatments for diabetes and the complications associated with it are essential. ${ }^{(1)}$

The three main therapeutic strategies for type 2 diabetes are diet, exercise, and pharmacotherapy. The third has serious side effects such as hypoglycemia and lactic acidosis. It is important to select therapeutic agents on the basis of individual patient condition and disease progression. ${ }^{(2)}$ In recent years, antidiabetic agents with new modes of action have been developed. Complexation pharmacotherapy is also being evaluated.

Type 2 diabetes is also controlled by exercise. Regular exercise substantially influences the development of diabetes, hypertension, and dyslipidemia. It also improves and maintains overall health, prevents lifestyle-related diseases, and prolongs healthy life expectancy. A study conducted on type 2 diabetic patients undergoing aerobic exercise for over 8 weeks disclosed that the maximum oxygen uptake in the exercise group was $12 \%$ higher than that of the non-exercising control group. Moreover, the exercise groups had superior cardiopulmonary function and HbAlc. ${ }^{(3)}$ However, certain patients have low exercise tolerance and capacity because of mutations in their energy production pathways. ${ }^{(4)}$ About $15-20 \%$ all of patients with type 2 diabetes present with inconsequential decreases in blood glucose level even after regular exercise. ${ }^{(5)}$ Overall, exercise increases muscle mass, mitigates obesity, improves cardiopulmonary function, and increases insulin sensitivity. ${ }^{(6,7)}$

Hayashi et al. ${ }^{(8)}$ reported that exercise increases insulin sensitivity by enhancing insulin-independent glucose uptake. This mechanism is mediated by muscle contraction-induced activation of AMP-activated protein kinase (AMPK) and glucose transporter 4 (GLUT4) which govern transmembrane glucose transport.

Hickey et $a l .{ }^{(9)}$ reported that the proportion of type I skeletal muscle fibers rich in GLUT4 and mitochondrial mass were lower in obese patients with type 2 diabetes than they were in non-obese patients. Exercise tends to increases type I skeletal muscle fiber density, and exercise-mediated skeletal muscle transformation may also enhance insulin sensitivity.

Exercise is closely associated with trace element levels. Iron, manganese, and copper are antioxidants, cofactors in glucosemetabolizing enzymes, and enzyme inducers. Both the deficiency and excess of these metal cations may cause functional impairment. Measurement of the fluctuations in trace elements caused by exercise may help evaluate exercise performance and diagnose pathological conditions. ${ }^{(10,11)}$ Athletes take iron supplements to replenish losses incurred by sweating and exercise anemia. ${ }^{(12)}$ Copper, manganese, and selenium (Se) are cofactors in enzymes removing excess active oxygen generated by exercise and protecting cells, tissues, and organs against oxidative stress. ${ }^{(13)}$ Earlier studies on obese rats reported that exercise increased blood and pancreatic zinc levels ${ }^{(14)}$ and altered hepatic element distribution. ${ }^{(15)}$ However, few studies have investigated the relationship between in vivo trace elements and exercise or their influences on protein synthesis and energy metabolism.

It was recently reported that Se-containing proteins are associated with exercise performance and diabetic status. ${ }^{(16)}$ Selenoprotein $\mathrm{P}$ is secreted to blood circulation from the liver, transports its abundant Se to all peripheral tissues, and protects against oxida-

*To whom correspondence should be addressed.

E-mail: y-yoshikawa@yg.kobe-wu.ac.jp (YY), yasui@mb.kyoto-phu.ac.jp (HY) 
tive stress by upregulating glutathione peroxidase (GPX) 1 activity. Misu et al. ${ }^{(17)}$ reported that blood selenoprotein $\mathrm{P}$ concentrations were elevated in diabetic patients. Selenoprotein $\mathrm{P}$ eliminates reactive oxygen species (ROS) generated during exercise. Then, selenoprotein P may act on the liver and skeletal muscles, cause reductive stress, and reversely induce type 2 diabetes. Therefore, it may contribute to exercise intolerance by mitigating the healthpromoting effects of exercise. ${ }^{(18)}$

Here, we investigated the effects of exercise on biological responsiveness in healthy and unhealthy experimental animals. We studied the effects of exercise on the in vivo trace elements, selenoprotein $\mathrm{P}$ expression, and other in vivo parameters. To this end, we used rats with obesity and high fructose-induced glucose intolerance and compared them with healthy animals.

\section{Materials and Methods}

Animal care. Male Wistar rats aged 4 weeks were obtained from CLEA Japan (Tokyo, Japan). All animals were housed in a temperature-controlled $\left(22 \pm 2^{\circ} \mathrm{C}\right)$ environment under a 12 -h light/dark cycle and had ad libitum food and water access. The rats were fed a standard MF diet (Oriental Yeast, Tokyo, Japan) for the first week followed by either a $20 \%(\mathrm{w} / \mathrm{w})$ casein diet $(\mathrm{CA})$ or a high-fructose diet [HF; $58 \%(\mathrm{w} / \mathrm{w})$ fructose] from ages $5-15$ weeks. The diet compositions are described in Table 1.

At 5 weeks, the rats were divided into the following four groups as follows; (1) $20 \%$ casein diet + no exercise [CA (-)]; (2) $20 \%$ casein diet + exercise [CA (ex)]; (3) high-fructose diet + no exercise $[\mathrm{HF}(-)]$; and (4) high-fructose diet + exercise [HF (ex)]. Each group was fed the corresponding diet for 10 weeks.

Body weight and food intake was measured weekly. At 15 weeks, the rats were euthanized by isoflurane after $16 \mathrm{~h}$ fasting. Blood was drawn from the abdominal aorta and transferred to heparin-coated vials. Plasma was prepared $(1,000 \mathrm{~g}, 10 \mathrm{~min})$ and stored at $-30^{\circ} \mathrm{C}$ until further analysis. Liver, kidney, pancreas, and soleus muscle were collected and then stored at $-30^{\circ} \mathrm{C}$. Liver tissue samples were frozen in liquid nitrogen and stored at $-80^{\circ} \mathrm{C}$ prior to PCR and western blotting analyses.

All animal experiments were conducted in accordance with the Guidelines for Animal Experimentation of Kobe Women's University, Kobe, Japan. The research protocol was approved by the Animal Experiment Committee of Kobe Women's University, Kobe, Japan (Approval No. A186).

Exercise training. Rats aged 5 weeks in the exercise training groups were subjected to 10 weeks (6 days/week) of exercise. They ran for $1 \mathrm{~h}$ /day on a treadmill (MK-680; Muromachi Kikai, Tokyo, Japan) inclined at $0^{\circ}$ grade and moving at $30 \mathrm{~m} / \mathrm{min}$.

Glucose tolerance test. At 13 weeks, the rats were intraperitoneally administered glucose $(2.0 \mathrm{~g} / \mathrm{kg})$ after a 16 -h overnight fast. Their blood glucose levels were measured at $0,15,30,60,90$,

Table 1. Composition of experimental diet

\begin{tabular}{lcc}
\hline Composition $\left(\mathrm{g} 100 \mathrm{~g}^{-1}\right.$ diet) & CA & $\mathrm{HF}$ \\
\hline Casein & 20 & 20 \\
Soybean oil & 6 & 6 \\
OYC mineral mix & 6 & 6 \\
OYC vitamin mix & 1 & 1 \\
Cellulose & 4 & 4 \\
Cornstarch & 48 & 5 \\
Sucrose & 15 & - \\
Fructose & - & 58 \\
\hline Calories (kcal $\left.100 \mathrm{~g}^{-1}\right)$ & 358 & 362 \\
Protein (\%) & 19.3 & 19.1 \\
Carbohydrates (\%) & 62.9 & 68.8 \\
Fat (\%) & 16.7 & 15.8 \\
\hline CA, $20 \%$ casein
\end{tabular}

CA, $20 \%$ casein diet; $\mathrm{HF}$, high-fructose diet (58\% fructose). and $120 \mathrm{~min}$. Blood glucose levels were determined by the glucose-oxidase method with Glucocard MyDIA (Arkray, Kyoto, Japan). Glucose tolerance was determined from the area under the curve of glucose concentration (AUC; 0-120 min).

Lactic acid measurement. At 15 weeks, blood was drawn from the caudal veins of the rats immediately after completion of exercise training. For the groups not being exercised, blood was sampled in the resting state. Lactic acid levels were determined with Lactate Pro2 (Arkray).

Blood biochemical analyses. Plasma high-density lipoprotein cholesterol (HDL-cho), total cholesterol (T-cho), triglyceride (TG), blood urea nitrogen (BUN), aspartate aminotransferase (AST), alanine aminotransferase (ALT), total protein (TP), creatine phosphokinase (CPK), creatinine (CRE), and glucose (GLU) were measured with an automatic dry-chemistry analyzer (Fuji Dri-Chem 3500V; Fujifilm Medical, Tokyo, Japan).

Plasma insulin measurement. Plasma insulin was determined with a Morinaga Ultrasensitive Rat Insulin ELISA Kit (Morinaga Institute of Biological Science, Kanagawa, Japan).

Trace element analysis. Fifty microliters plasma and $30 \mathrm{mg}$ each of the liver, kidney, and pancreas samples were placed in $50 \mathrm{ml}$ tall beakers and heated on hotplates to $150^{\circ} \mathrm{C}$. Then $2 \mathrm{ml}$ of $60 \%$ (v/v) nitric acid $\left(\mathrm{HNO}_{3}\right.$; Kanto Chemical, Tokyo, Japan) was added. After $3 \mathrm{~min}, 2 \mathrm{ml}$ of $60 \%$ (v/v) perchloric acid $\left(\mathrm{HClO}_{4}\right.$; Kishida Chemical, Osaka, Japan) was added. After another 3 min, $2 \mathrm{ml}$ of $30 \%(\mathrm{v} / \mathrm{v})$ hydrogen peroxide $\left(\mathrm{H}_{2} \mathrm{O}_{2}\right.$; Kishida Chemical) was added. This process was repeated thrice. Then another $2 \mathrm{ml}$ of $30 \%(\mathrm{v} / \mathrm{v}) \mathrm{H}_{2} \mathrm{O}_{2}$ was added and the samples were heated until digestion was complete. The liquid was evaporated and the sample residues were cooled. Then $9 \mathrm{ml}$ of $5 \%(\mathrm{v} / \mathrm{v}) \mathrm{HNO}_{3}$ was added and the residues were dissolved for $3 \mathrm{~h}$. The solutions were then transferred to sample cups. All tall beakers and sample cups used in this experiment were pretreated with $1 \%(\mathrm{v} / \mathrm{v}) \mathrm{HNO}_{3}$ to avoid metal contamination. The trace elements [calcium $(\mathrm{Ca})$, magnesium $(\mathrm{Mg})$, copper $(\mathrm{Cu})$, iron $(\mathrm{Fe})$, manganese $(\mathrm{Mn})$, zinc $(\mathrm{Zn})$, chromium $(\mathrm{Cr})$, and $\mathrm{Se}]$ in the solutions were identified and quantitated by inductively coupled plasma-mass spectrometry (ICP-MS; Agilent7700/Mass Hunter, Agilent Technologies, Santa Clara, CA). Standard curves were plotted by preparing 1,000-ppm standard solutions of $\mathrm{Ca}, \mathrm{Mg}, \mathrm{Cu}, \mathrm{Fe}, \mathrm{Mn}, \mathrm{Zn}, \mathrm{Cr}$, and $\mathrm{Se}$ (Fujifilm Wako Pure Chemical Industries Ltd., Osaka, Japan) and diluting them in $5 \%(\mathrm{v} / \mathrm{v}) \mathrm{HNO}_{3}$ to final metal concentrations of $0,1,5,50$, 100 , and $500 \mathrm{ppb}$. For quality control, $1 \mathrm{ppm}$ of a reference internal standard (indium; In) was measured along with the samples.

Measurement of artificial superoxide anion production. Superoxide anion $\left(\mathrm{O}_{2}^{-{ }^{-}}\right)$was generated from the reaction between hypoxanthine and xanthine oxidase. For the hepatic and renal superoxide anion measurements, 2-methyl-6- $p$-methoxyphenylethynylimidazopyrazinone (MPEC) was used to induce oxidation. Xanthine oxidase and hypoxanthine were prepared in phosphate buffer $\left(0.1 \mathrm{M} \mathrm{KH}_{2} \mathrm{PO}_{4}\right.$ buffer, $\left.\mathrm{pH} 7.5\right)$. The reaction solution for the superoxide anion scavenging activity test consisted of $60 \mu \mathrm{l}$ crude hepatic or renal enzyme solution, $10 \mu \mathrm{l}$ of $300 \mu \mathrm{M}$ MPEC, $170 \mu \mathrm{l}$ of $0.1 \mathrm{M} \mathrm{KH}_{2} \mathrm{PO}_{4}$ buffer, $60 \mu \mathrm{l}$ xanthine oxidase solution $(0.1 \mathrm{U} / \mathrm{ml})$ and $50 \mu \mathrm{l}$ of $3.6 \mathrm{mM}$ hypoxanthine $/ \mathrm{KH}_{2} \mathrm{PO}_{4}$. Crude hepatic or renal enzyme solutions were obtained from sample homogenates prepared in phosphate-buffered saline (PBS) as follows: $0.1 \mathrm{~g}$ liver or kidney isolates were homogenized in $500 \mu \mathrm{l}$ of $0.1 \mathrm{M}$ PBS ( $\mathrm{pH} 7.3$ ) and the homogenized samples were centrifuged at $1,800 \mathrm{~g}$ and $4^{\circ} \mathrm{C}$ for $15 \mathrm{~min}$. The supernatants were collected and used as crude hepatic or renal enzyme solutions. The reaction was initiated by adding hypoxanthine. Fifty microliters of the reaction solution was placed in each Röhren tube $(5 \mathrm{ml}$; $75 \mathrm{~mm} \times 12 \mathrm{~mm}$; Sarstedt, Nümbrecht, Germany) and MPEC light emission was measured with a luminometer (Lumat3 LB9508; Berthold Technologies, Bad Wildbad, Germany).

Muscle glycogen measurement. Muscle glycogen was measured by the phenol-sulfuric acid method. A $0.5 \mathrm{~g}$ soleus 
muscle was dissolved in $3 \mathrm{ml}$ of $30 \%(\mathrm{w} / \mathrm{v})$ potassium hydroxidesaturated sodium sulfate solution $\left[30 \%(\mathrm{w} / \mathrm{v}) \mathrm{KOHNa}_{2} \mathrm{SO}_{4}\right]$ in a boiling water bath for $30 \mathrm{~min}$. After cooling on ice, the solution was extracted with $5 \mathrm{ml}$ of $95 \%(\mathrm{v} / \mathrm{v})$ ethanol $\left[95 \%(\mathrm{v} / \mathrm{v}) \mathrm{C}_{2} \mathrm{H}_{5} \mathrm{OH}\right]$ and cooled again. The extract was centrifuged at $1,700 \mathrm{~g}$ and $4{ }^{\circ} \mathrm{C}$ for $30 \mathrm{~min}$ and the supernatant was discarded. The pellet was dissolved in $5 \mathrm{ml}$ distilled water and diluted to $10 \mathrm{ml}$ with distilled water. Then $0.5 \mathrm{ml}$ of the glycogen extract was mixed with $0.5 \mathrm{ml}$ of $5 \%(\mathrm{v} / \mathrm{v})$ phenol and $2.5 \mathrm{ml}$ concentrated hydrochloric acid $(\mathrm{HCl})$. This mixture was incubated for $20 \mathrm{~min}$ at $25^{\circ} \mathrm{C}$. Absorbance was read at $490 \mathrm{~nm}$ in a spectrophotometer (UV-1280; Shimadzu Corp., Kyoto, Japan).

RNA isolation, cDNA synthesis, and PCR for hepatic selenoprotein P. Frozen liver tissue stored at $-80^{\circ} \mathrm{C}$ was soaked in RNA later-ICE frozen tissue transition solution (Thermo Fisher Scientific, Waltham, MA) at $-20^{\circ} \mathrm{C}$ for $\geq 16 \mathrm{~h}$. Total RNA was isolated with a high pure RNA tissue kit (Roche Diagnostics, Basel, Switzerland). The cDNA synthesis and PCR were performed with a One Step SYBR PrimeScript Plus RT-PCR kit (Takara Bio Inc., Shiga, Japan) according to the manufacturer's instructions. The mRNA expression of selenoprotein P was analyzed in a LightCycler Nano (Roche Diagnostics). The PCR amplicons were quantified with LightCycler software (Roche Diagnostics). Data were internally normalized to the $\beta$-actin housekeeping gene whose primer sequences were previously described. Target primers were designed with the Universal Probe Library Assay Design Center (Roche Diagnostics). Their specificities were confirmed by melting curve analysis. Following are the target primer sequences: rat $\beta$-actin: R: GCGGCAGTGGCCATCTC, L: GGG AAATCGTGCGTGACATT; rat selenoprotein P: R: TGTCAC GACCAAATGTGGAG, L: GGAGAAAAGAGAGGGTGCAA. The PCR conditions were as follows: initial denaturation at $95^{\circ} \mathrm{C}$ for $10 \mathrm{~s}$ followed by 40 cycles of denaturation at $95^{\circ} \mathrm{C}$ for $5 \mathrm{~s}$, annealing at $60^{\circ} \mathrm{C}$ for $30 \mathrm{~s}$, and extension at $72^{\circ} \mathrm{C}$ for $3 \mathrm{~s}$.

Statistical analysis. Data are means \pm SD. Differences between the means for $\mathrm{CA}(-)$ and $\mathrm{CA}(\mathrm{ex})$ and those between the means for HF(-) and HF(ex) were compared by Student's $t$ test at the $* p<0.05$ and $* * p<0.01$ significance levels, respectively.

\section{Results}

General characteristics. Only male Wistar rats were used in the present study. Body, liver, and genital adipose tissue weights and food intake were significantly lower $(p=0.004, p=0.042$, $p=0.004$, and $p=0.029$, respectively) in the rats maintained on HF diets and exercised than in those that were not exercised. These parameters also decreased for the rats fed CA but their values did not significantly differ $(p=0.422, p=0.139, p=0.228$, and $p=0.250$, respectively) between those that were exercised and those that were not exercised (Table 2).

Glucose tolerance test. The rate of decreased blood glucose concentration below the peak was higher in the exercised rats than the non-exercised rats, especially for those on the HF diets (Fig. 1A). Additionally, the AUC values were lower in the exercised rats than the non-exercised rats, which were maintained on $\mathrm{HF}$ diets (Fig. 1B).

Plasma insulin measurement. Blood insulin levels were lower in the exercised than the non-exercised rats in both experimental diet groups (Fig. 2).

Lactic acid measurement. Lactic acid levels were lower in the exercised than the non-exercised rats (Fig. 3) in both experimental diet groups. The exercised rats maintained on HF presented significantly lower $(p=0.001)$ lactic acid levels than those that were exercised.

Table 2. General characteristics of animals

\begin{tabular}{|c|c|c|c|c|}
\hline \multirow{3}{*}{$\begin{array}{l}\text { Experimental diet } \\
\text { Exercise training }\end{array}$} & \multicolumn{4}{|c|}{ Groups } \\
\hline & \multicolumn{2}{|c|}{ CA } & \multicolumn{2}{|c|}{$\mathrm{HF}$} \\
\hline & $(-)$ & (ex) & $(-)$ & (ex) \\
\hline Body weight (g) & $397 \pm 41$ & $378 \pm 10$ & $409 \pm 19$ & $363 \pm 9 * *$ \\
\hline Food intake (g/day) & $22.2 \pm 3.1$ & $20.7 \pm 0.4$ & $21.7 \pm 0.7$ & $17.4 \pm 0.7^{*}$ \\
\hline Liver ( $g / 100 \mathrm{~g}$ of body weight) & $2.9 \pm 0.3$ & $2.7 \pm 0.1$ & $3.0 \pm 0.2$ & $2.7 \pm 0.1$ * \\
\hline Genital adipose tissue ( $\mathrm{g} / 100 \mathrm{~g}$ of body weight) & $1.5 \pm 0.2$ & $1.4 \pm 0.1$ & $1.9 \pm 0.2$ & $1.5 \pm 0.1$ ** \\
\hline
\end{tabular}

Data are means \pm SD. ${ }^{*} p<0.05$ and ${ }^{* *} p<0.01$ vs each diet (-) group. CA (-), $n=3$; CA (ex), HF (-), and HF (ex), $n=4$.
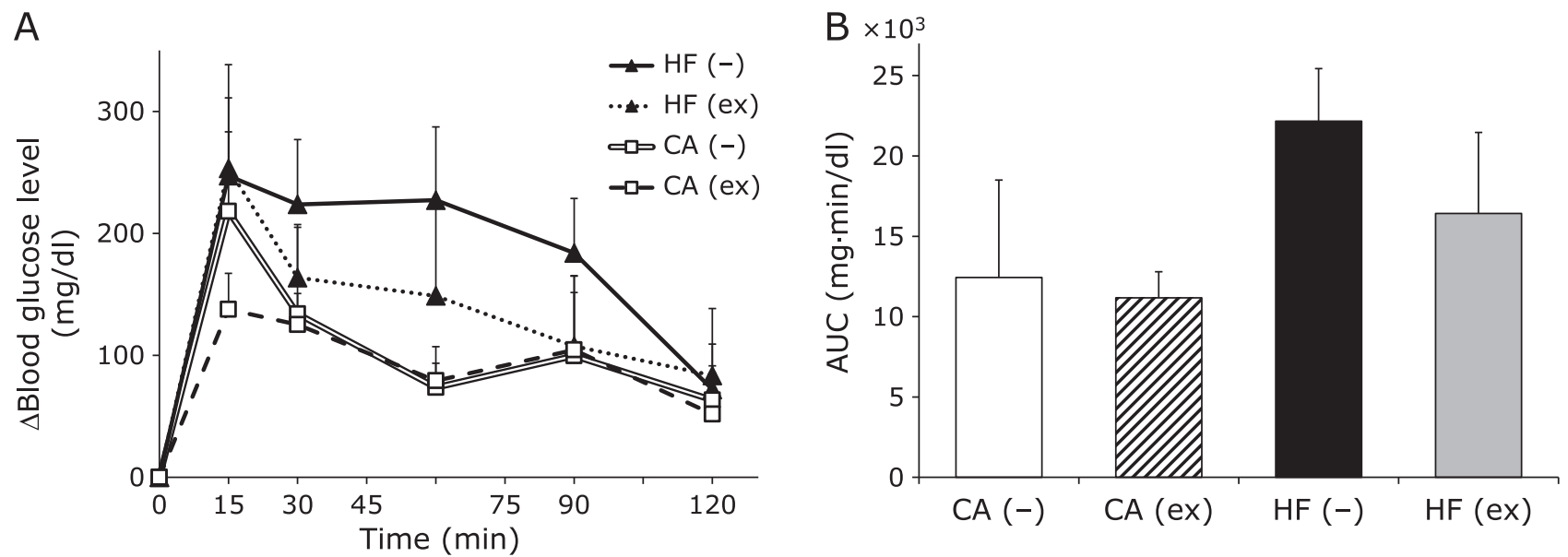

Fig. 1. Changes in blood glucose during glucose tolerance test (A) and area under curve (AUC) of blood glucose (B). Data are means $\pm S D$. CA (-), $n=3$; CA (ex), HF (-), and HF (ex), $n=4$. 


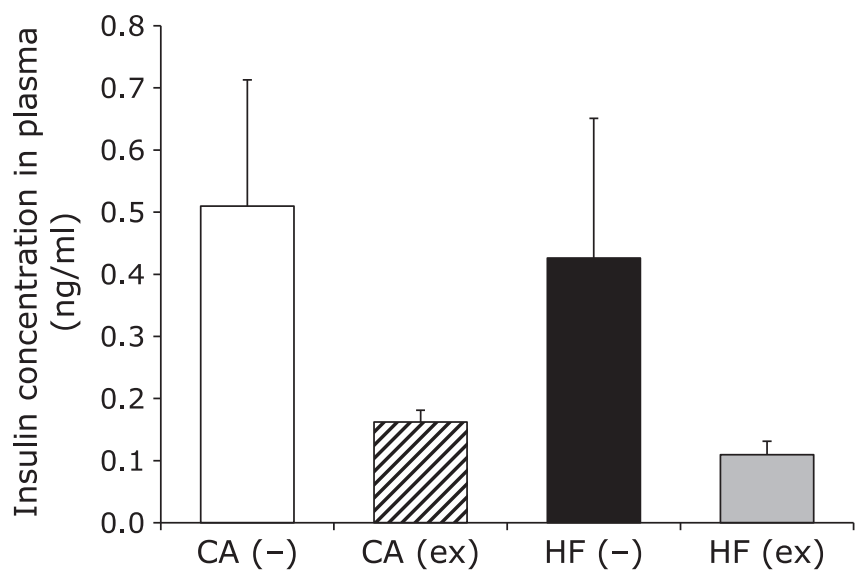

Fig. 2. Changes in plasma insulin concentration. Data are means $\pm S D$. CA (-), $n=3$; CA (ex), HF (-), and HF (ex), $n=4$.

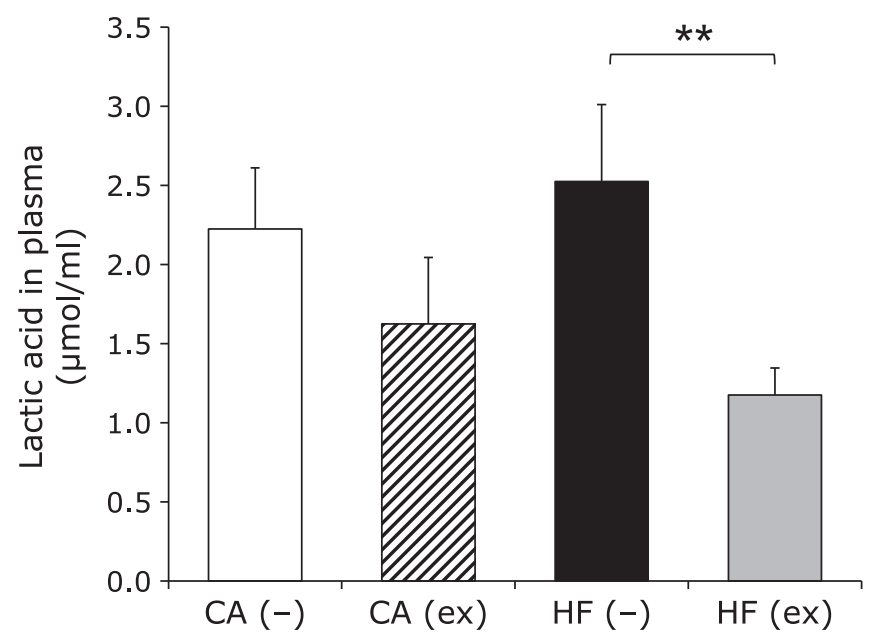

Fig. 3. Measurement of lactic acid level in plasma. Data are means $\pm S D$. ${ }^{*} p<0.01$ vs each diet (-) group. CA (-), $n=3$; CA (ex), HF (-), and HF (ex), $n=4$.

Table 3. Blood biochemical analysis

\begin{tabular}{|c|c|c|c|c|}
\hline \multirow{3}{*}{$\begin{array}{l}\text { Experimental diet } \\
\text { Exercise training }\end{array}$} & \multicolumn{4}{|c|}{ Groups } \\
\hline & \multicolumn{2}{|c|}{ CA } & \multicolumn{2}{|c|}{$\mathrm{HF}$} \\
\hline & $(-)$ & (ex) & $(-)$ & (ex) \\
\hline HDL-cho $\left(\mathrm{mg} \mathrm{dl}^{-1}\right)$ & $41 \pm 9$ & $37 \pm 4$ & $51 \pm 10$ & $49 \pm 7$ \\
\hline T-cho (mg dl-1) & $59 \pm 8$ & $58 \pm 3$ & $70 \pm 8$ & $67 \pm 11$ \\
\hline TG $\left(m g \mathrm{dl}^{-1}\right)$ & $104 \pm 24$ & $64 \pm 15^{*}$ & $134 \pm 41$ & $73 \pm 1$ \\
\hline $\operatorname{BUN}\left(m g \mathrm{dl}^{-1}\right)$ & $14 \pm 5$ & $14 \pm 1$ & $16 \pm 2$ & $18 \pm 2$ \\
\hline AST $\left(U L^{-1}\right)$ & $62 \pm 0$ & $87 \pm 27$ & $60 \pm 1$ & $78 \pm 18$ \\
\hline $\operatorname{ALT}\left(\mathrm{UL}^{-1}\right)$ & $29 \pm 6$ & $34 \pm 6$ & $24 \pm 3$ & $39 \pm 5$ \\
\hline $\mathrm{TP}\left(\mathrm{g} \mathrm{dl}^{-1}\right)$ & $6.2 \pm 0.1$ & $5.9 \pm 0.2$ & $5.9 \pm 0.2$ & $5.7 \pm 0.2$ \\
\hline CPK $\left(U L^{-1}\right)$ & $88 \pm 25$ & $80 \pm 18$ & $88 \pm 10$ & $106 \pm 41$ \\
\hline CRE (mg dl-1) & $0.2 \pm 0.1$ & $0.3 \pm 0.1$ & $0.2 \pm 0.1$ & $0.2 \pm 0.1$ \\
\hline $\mathrm{GLU}\left(\mathrm{mg} \mathrm{dl}^{-1}\right)$ & $175 \pm 17$ & $174 \pm 6$ & $178 \pm 17$ & $125 \pm 20$ ** \\
\hline
\end{tabular}

Data are means \pm SD. ${ }^{*} p<0.05$ and ${ }^{*} * p<0.01$ vs each diet (-) group. CA $(-), n=3$; CA (ex), HF (-), and HF (ex), $n=4$.

Blood biochemical analysis. Blood AST and ALT concentrations were higher in the exercised than the non-exercised rats in both experimental diet groups [ALT: CA group, $p=0.057$ vs $(-)$ group]. The blood TG and GLU levels were lower in the exercised rats than those in the non-exercised rats [TG: HF-fed group, $p=0.053$ vs (-) group]. (Table 3 ).

Muscle glycogen level measurement. The muscle glycogen levels were significantly higher $(p=0.045)$ in exercised CA-fed rats than in those that were not exercised. While, there were no significant differences between the exercised and non-exercised HF-fed rats in terms of muscle glycogen level (Fig. 4).

Trace element analysis. Plasma Fe, $\mathrm{Zn}$, and Se levels were lower in the exercised than the non-exercised rats in both experimental diet groups (Table 4A). Hepatic $\mathrm{Mg}, \mathrm{Mn}, \mathrm{Fe}, \mathrm{Cu}$, and $\mathrm{Zn}$ levels increased in response to exercise (Table 4B). Renal $\mathrm{Ca}$ and $\mathrm{Cr}$ levels increased in response to exercise in both experimental diet groups (Table 4C). The levels of several pancreatic trace elements decreased in HF-fed rats in response to exercise (Table 4D).

Superoxide anion production measurement. Artificial superoxide anion production in hepatic and renal solutions increased in response to exercise in both experimental diet groups (Fig. 5A and B).

RNA isolation, CDNA synthesis, and PCR analysis of selenoprotein P. Hepatic selenoprotein P mRNA was significantly upregulated in the exercised rats compared to those that were not exercised, particularly for those on the CA diet (Fig. 6).

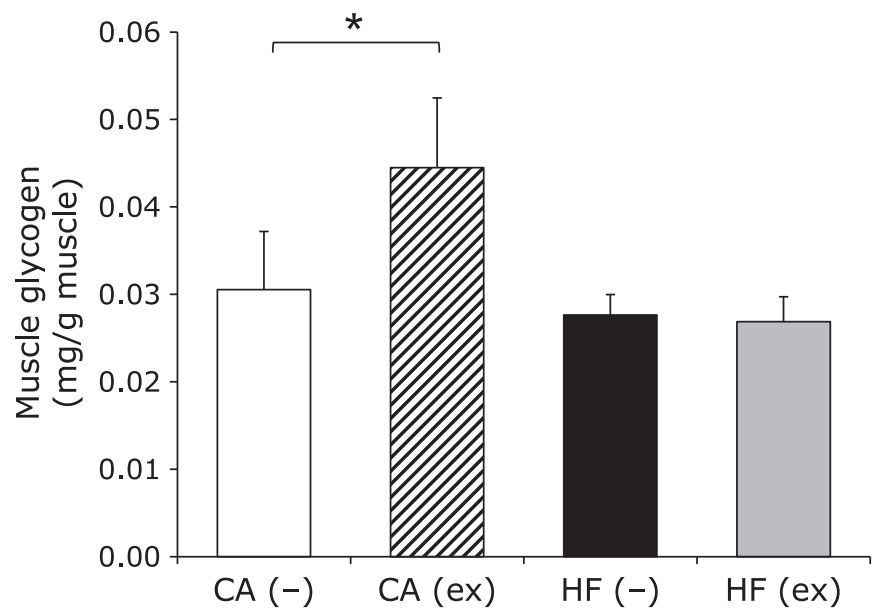

Fig. 4. Measurement of muscle glycogen levels. Data are means $\pm S D$ ${ }^{*} p<0.05$ vs each diet (-) group. CA $(-), n=3 ;$ CA (ex), HF (-), and HF (ex), $n=4$. 
Table 4. Trace element concentrations in plasma (A), liver (B), kidney (C), and pancreas (D)

\begin{tabular}{|c|c|c|c|c|c|}
\hline \multirow[t]{10}{*}{$A$} & \multirow{2}{*}{ Plasma } & \multicolumn{2}{|c|}{$\mathrm{CA}(\mu \mathrm{g} / \mathrm{ml})$} & \multicolumn{2}{|c|}{$\mathrm{HF}(\mu \mathrm{g} / \mathrm{ml})$} \\
\hline & & $(-)$ & (ex) & $(-)$ & (ex) \\
\hline & $\mathrm{Mg}$ & $51.0 \pm 3.4$ & $47.6 \pm 3.1$ & $39.9 \pm 6.3$ & $41.8 \pm 7.8$ \\
\hline & $\mathrm{Ca}$ & $210.1 \pm 7.5$ & $196.3 \pm 18.1$ & $195.4 \pm 18.9$ & $194.2 \pm 13.1$ \\
\hline & $\mathrm{Cr}$ & $0.08 \pm 0.00$ & $0.09 \pm 0.02$ & $0.06 \pm 0.00$ & $0.06 \pm 0.00$ \\
\hline & $\mathrm{Mn}$ & $0.02 \pm 0.02$ & $0.05 \pm 0.01$ & $0.05 \pm 0.01$ & $0.04 \pm 0.01$ \\
\hline & $\mathrm{Fe}$ & $5.4 \pm 0.6$ & $4.6 \pm 0.1 *$ & $4.6 \pm 0.7$ & $3.8 \pm 0.4$ \\
\hline & $\mathrm{Cu}$ & $2.1 \pm 0.1$ & $2.0 \pm 0.0$ & $2.2 \pm 0.1$ & $2.2 \pm 0.1$ \\
\hline & $\mathrm{Zn}$ & $0.9 \pm 0.4$ & $0.7 \pm 0.1$ & $1.1 \pm 0.1$ & $1.0 \pm 0.1$ \\
\hline & $\mathrm{Se}$ & $0.41 \pm 0.27$ & $0.14 \pm 0.13$ & $0.25 \pm 0.29$ & $0.22 \pm 0.28$ \\
\hline \multirow[t]{10}{*}{ B } & \multirow{2}{*}{ Liver } & \multicolumn{2}{|c|}{ CA ( $\mu \mathrm{g} / \mathrm{g}$ of wet weight) } & \multicolumn{2}{|c|}{ HF ( $\mu \mathrm{g} / \mathrm{g}$ of wet weight) } \\
\hline & & $(-)$ & (ex) & $(-)$ & (ex) \\
\hline & $\mathrm{Mg}$ & $204.1 \pm 8.7$ & $234.5 \pm 12.1 *$ & $231.4 \pm 15.5$ & $234.1 \pm 3.4$ \\
\hline & $\mathrm{Ca}$ & $51.7 \pm 3.5$ & $59.2 \pm 5.3$ & $60.7 \pm 5.6$ & $59.4 \pm 7.1$ \\
\hline & $\mathrm{Cr}$ & $0.17 \pm 0.00$ & $0.17 \pm 0.01$ & $0.15 \pm 0.01$ & $0.18 \pm 0.03$ \\
\hline & $\mathrm{Mn}$ & $2.02 \pm 0.19$ & $2.40 \pm 0.17^{*}$ & $2.83 \pm 0.32$ & $3.44 \pm 0.49$ \\
\hline & $\mathrm{Fe}$ & $183.5 \pm 33.8$ & $229.8 \pm 22.5$ & $189.1 \pm 28.2$ & $196.3 \pm 26.5$ \\
\hline & $\mathrm{Cu}$ & $4.2 \pm 0.6$ & $5.5 \pm 0.5^{*}$ & $4.9 \pm 0.1$ & $5.8 \pm 1.0$ \\
\hline & $\mathrm{Zn}$ & $30.0 \pm 0.9$ & $35.3 \pm 1.2 * *$ & $31.4 \pm 0.9$ & $36.4 \pm 4.8$ \\
\hline & $\mathrm{Se}$ & $0.31 \pm 0.14$ & $0.22 \pm 0.19$ & $0.30 \pm 0.10$ & $0.34 \pm 0.14$ \\
\hline \multirow[t]{10}{*}{ C } & \multirow{2}{*}{ Kidney } & \multicolumn{2}{|c|}{ CA ( $\mu \mathrm{g} / \mathrm{g}$ of wet weight) } & \multicolumn{2}{|c|}{$\mathrm{HF}$ ( $\mu \mathrm{g} / \mathrm{g}$ of wet weight) } \\
\hline & & $(-)$ & (ex) & $(-)$ & (ex) \\
\hline & $\mathrm{Mg}$ & $197.3 \pm 31.5$ & $187.5 \pm 7.2$ & $189.9 \pm 19.3$ & $197.5 \pm 6.9$ \\
\hline & $\mathrm{Ca}$ & $90.5 \pm 10.5$ & $108.8 \pm 24.3$ & $282.6 \pm 191.3$ & $342.7 \pm 199.5$ \\
\hline & $\mathrm{Cr}$ & $0.13 \pm 0.04$ & $0.17 \pm 0.01$ & $0.12 \pm 0.03$ & $0.13 \pm 0.02$ \\
\hline & $\mathrm{Mn}$ & $1.01 \pm 0.25$ & $0.92 \pm 0.01$ & $1.06 \pm 0.26$ & $1.05 \pm 0.08$ \\
\hline & $\mathrm{Fe}$ & $82.9 \pm 90.6$ & $70.3 \pm 6.2$ & $68.8 \pm 12.7$ & $67.5 \pm 4.7$ \\
\hline & $\mathrm{Cu}$ & $7.6 \pm 5.5$ & $7.5 \pm 1.3$ & $13.2 \pm 6.5$ & $7.6 \pm 1.9$ \\
\hline & $\mathrm{Zn}$ & $23.2 \pm 15.7$ & $33.6 \pm 4.3$ & $33.9 \pm 8.2$ & $34.4 \pm 5.6$ \\
\hline & $\mathrm{Se}$ & ud & $0.18 \pm 0.17$ & $0.05 \pm 0.06$ & ud \\
\hline \multirow[t]{10}{*}{$\mathrm{D}$} & \multirow{2}{*}{ Pancreas } & \multicolumn{2}{|c|}{ CA ( $\mu \mathrm{g} / \mathrm{g}$ of wet weight) } & \multicolumn{2}{|c|}{$\mathrm{HF}$ ( $\mu \mathrm{g} / \mathrm{g}$ of wet weight) } \\
\hline & & $(-)$ & (ex) & $(-)$ & (ex) \\
\hline & $\mathrm{Mg}$ & $342.7 \pm 16.1$ & $326.0 \pm 36.4$ & $330.7 \pm 41.6$ & $311.4 \pm 17.1$ \\
\hline & $\mathrm{Ca}$ & $102.4 \pm 25.3$ & $97.7 \pm 21.9$ & $107.2 \pm 21.2$ & $104.6 \pm 12.7$ \\
\hline & $\mathrm{Cr}$ & $0.22 \pm 0.03$ & $0.24 \pm 0.06$ & $0.24 \pm 0.03$ & $0.18 \pm 0.03$ \\
\hline & $\mathrm{Mn}$ & $2.18 \pm 0.04$ & $2.01 \pm 0.20$ & $2.52 \pm 0.22$ & $2.47 \pm 0.20$ \\
\hline & $\mathrm{Fe}$ & $22.8 \pm 1.2$ & $21.9 \pm 0.6$ & $25.3 \pm 5.4$ & $19.8 \pm 1.2$ \\
\hline & $\mathrm{Cu}$ & $1.5 \pm 0.1$ & $1.6 \pm 0.1$ & $1.5 \pm 0.2$ & $1.3 \pm 0.1$ \\
\hline & $\mathrm{Zn}$ & $26.7 \pm 4.1$ & $27.4 \pm 3.6$ & $34.7 \pm 4.0$ & $31.1 \pm 4.2$ \\
\hline & $\mathrm{Se}$ & $0.22 \pm 0.08$ & $0.23 \pm 0.07$ & $0.20 \pm 0.15$ & $0.29 \pm 0.12$ \\
\hline
\end{tabular}

Data are means \pm SD. ${ }^{*} p<0.05$ and ${ }^{* *} p<0.01$ vs each diet (-) group. CA (-), $n=3$; CA (ex), HF (-), and HF (ex), $n=4$. ud: under determine.

\section{Discussion}

We investigated the effects of exercise intended to prevent and ameliorate disease on the expression of biological trace elements, selenoprotein $\mathrm{P}$, and other biochemical parameters in glucose intolerance condition. In this study, rats were exercised 6 days/week for 10 weeks.

The target of exercise therapy for diabetes is 20-60 min of midstrength aerobic exercise at $40-60 \%$ of the maximum oxygen uptake for at least 3-5 days/week. ${ }^{(19)}$ Endurance exercise at 50 $70 \%$ of the maximum oxygen uptake and lactic acid threshold is effective as a primary prophylaxis against diabetes. ${ }^{(20)}$ Therefore, we designed an exercise regimen that was more strenuous than that used in diabetic therapy. The exercise threshold was set to $\sim 70-80 \%$ of the maximum oxygen uptake. ${ }^{(21)}$ It consisted of treadmill running at $30 \mathrm{~m} / \mathrm{min}$ and $0^{\circ}$ inclination for $1 \mathrm{~h} /$ day and 6 days/week for 10 weeks. Since glucose intolerance and obesity are characteristic symptoms of type 2 diabetes, rats were fed $58 \%$ (w/w) high-fructose diets to induce the diabetic model. Fructose is rapidly metabolized in the liver, and does not induce the insulin secretion but causes insulin resistance and lipid metabolism disorders. $^{(22)}$

For both groups, rat weights and food intake decreased in response to exercise. These parameters markedly decreased for the exercised group with HF diet. Exercise reduces energy consumption by upregulating peptide YY and glucagon-like peptide-1, 

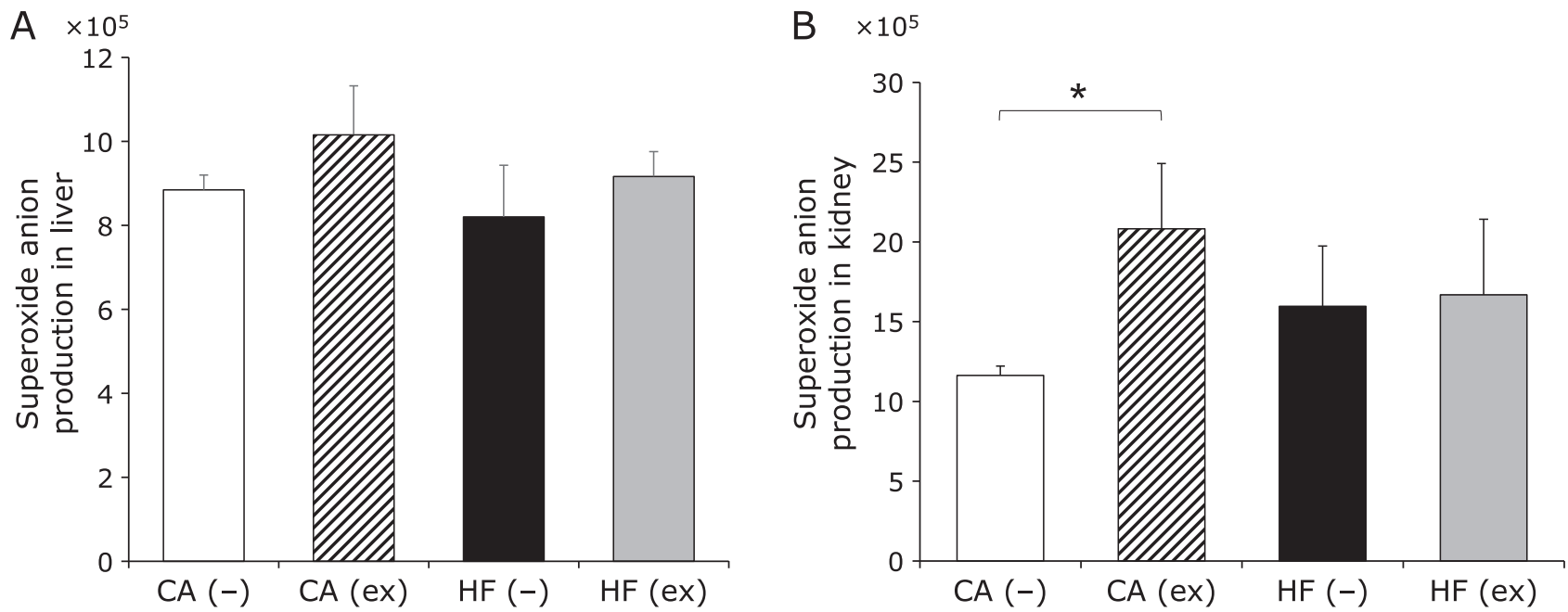

Fig. 5. Measurement of superoxide anion scavenging activity in liver (A) and kidney (B). Data are means \pm SD. * $p<0.05$ vs each diet (-) group. CA (-), $n=3 ; \mathrm{CA}(\mathrm{ex}), \mathrm{HF}(-)$, and HF (ex), $n=4$.

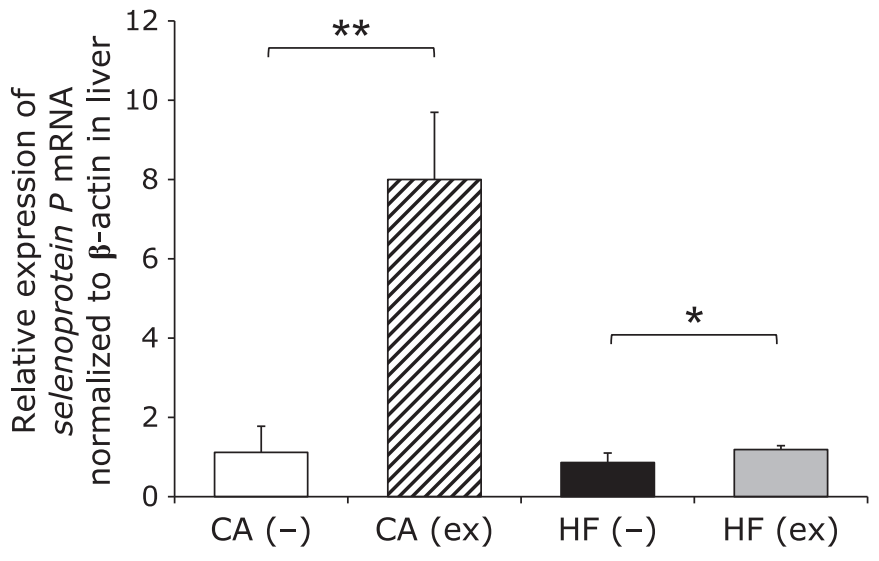

Fig. 6. Relative hepatic selenoprotein $P$ expression levels. Data are means \pm SD. ${ }^{*} p<0.05$ and ${ }^{*}{ }^{*} p<0.01$ vs each diet $(-)$ group. CA $(-), n=3$; CA (ex), HF (-), and HF (ex), $n=4$.

and these hormones regulate food intake. ${ }^{(23)}$ Additionally, exercise may reduce food intake via a stress response. ${ }^{(24)}$ Here, the rats in the exercised groups lost body weights because the exercise, digestive hormones, and stress response reducing food intake. Moreover, continuous exercise decreased epididymal fat mass (Table 2).

The glucose tolerance test data and plasma insulin levels indicated that exercise in the high-fructose group ameliorated glucose tolerance and reduced visceral fat mass (Table 2, Fig. 1 and 2). A previous study showed that exercise elevated glucose intake by increasing the muscle mass, number of mitochondria, and GLUT4 levels. ${ }^{(25)}$ Reduction in organ fat improves glucose intolerance by lowering plasma tumor necrosis factor- $\alpha$ (TNF- $\alpha$ ) and resistin and by raising plasma adiponectin which enhances insulin sensitivity. ${ }^{(26,27)}$ In the present study, the glucose intolerance and obesity group by a high-fructose diet presented significant decreases in epididymal fat mass and amelioration of glucose tolerance in response to continuous exercise.

Lactic acid is a glycogen catabolite formed by anaerobic respiration in the muscle after hard exercise. Lactic acid uptake depends on monocarboxylate transporter 1 (MCT1) expression levels, and MCT1 is upregulated in cardiac and soleus muscle which have high antioxidant capacity. Therefore, continuous exercise upregulates MCT1, ${ }^{(28)}$ while glucose and lactic acid metabolism and MCT1 expression are all diminished in diabetic patients. However, exercise enhances glucose and lactic acid metabolism and induces MCT1. ${ }^{(29)}$ In the present study, the significant decrement in plasma lactic acid was observed in the exercised HF group, indicating that exercise increases the lactic acid utilization ratio (Fig. 3 ).

The plasma biochemical parameters revealed that exercise decreased T-cho and TG which participate in lipid metabolism. Exercise also increased BUN, AST, and ALT (Table 3). The TG level in the CA group and the GLU level in the HF group significantly decreased in response to exercise. Exercise activates AMPK which, in turn, regulates gluconeogenesis, hepatic fatty acid oxidation, mitochondrial activation, and fatty acid metabolism in the muscle. ${ }^{(30)}$ The significant reductions of these biochemical parameters in the plasma levels suggested that exercise enhanced glucose and lipid metabolism.

BUN reflects kidney function. AST and ALT are enzymes produced in the liver, cardiac, and skeletal muscle. Plasma AST and ALT may increase in response to hard exercise, and AST and ALT upregulation may have accounted for our observed results. Increments in AST and ALT suggest that the exercise may have suppressed liver function.

To enable to sustain endurance exercise, skeletal muscles must resynthesize ATP from glycogen. Then, glycogen depletion causes muscle fatigue, and increasing muscle glycogen before exercise enhances stamina. ${ }^{(31)}$ In this study, exercise significantly increased muscle glycogen in normal rats and improved their endurance (Fig. 4). In contrast, it did not substantially increase glycogen in the muscles of rats with glucose intolerance and obesity compared those of non-exercised rats fed HF diet. Skeletal muscle consumes glucose and regulates blood glucose levels by converting and storing it as glycogen in the muscles and liver. In animals with glucose intolerance and obesity, however, the skeletal muscles do not uptake or consume enough blood glucose despite potential insulin secretion. Type 2 diabetes patients often present skeletal muscle weakness because their intracellular $\mathrm{Ca}$ ion levels are abnormal. ${ }^{(32)}$ There may also be dramatic differences between healthy rats and those with glucose intolerance and obesity in terms of their glucose metabolism. Certain studies reported that exercise improves mitochondrial function and upregulates GLUT4 in the muscle, and these effects may increase muscle glycogen storage. ${ }^{(33,34)}$ Nevertheless, from the results of the 
present study, it is suggested that exercise may not have sufficed to upregulate GLUT4 or ameliorate mitochondrial or GLUT4 dysfunction in rats with glucose intolerance and obesity.

We measured trace element levels in the plasma, liver, kidney, and pancreas by ICP-MS (Table 4) because several trace elements are associated with exercise and diabetes. $\mathrm{Mg}$ regulates electrolyte balance, governs muscle contraction, and controls blood glucose levels via enzymes induced by insulin. Type 2 diabetes patients often present hypomagnesemia. ${ }^{(35)} \mathrm{Cr}$ may also be therapeutic for diabetes, and may ameliorate insulin resistance by downregulating TNF- $\alpha$ and reducing lipid peroxide formation. Cr also upregulates insulin receptor kinase and enhances insulin sensitivity. ${ }^{(36)} \mathrm{Ca}$ and $\mathrm{Mg}$ participate in muscle contraction and bone growth. However, we observed no significant differences between the exercisedand non-exercised groups in terms of their organ $\mathrm{Ca}, \mathrm{Cr}$, or $\mathrm{Mg}$ levels except for those in the liver. Hepatic $\mathrm{Mg}, \mathrm{Mn}, \mathrm{Cu}$, and $\mathrm{Zn}$ levels were significantly higher in the exercised group than the non-exercised group. Exercise activated enzymatic reactions in the mitochondria and generated superoxide anion. However, living organisms produce superoxide dismutase (SOD) that protects their cells, tissues, and organs against superoxide anion. ${ }^{(37)}$ Some trace elements are essential for activation and stabilization of antioxidant enzymes. For example, SOD reducing $\mathrm{O}_{2}{ }^{--}$has $\mathrm{Cu}$, $\mathrm{Zn}$, and $\mathrm{Mn}$ ions as cofactors inside its molecule. GPX reducing hydrogen peroxide has Se at the reaction site of its molecule. In this study, exercise significantly increased $\mathrm{Mg}, \mathrm{Mn}, \mathrm{Cu}$ and $\mathrm{Zn}$ and somewhat increased $\mathrm{Fe}$ in the liver (Table 4B). Additionally, exercise elevated the levels of $\mathrm{Mn}, \mathrm{Fe}, \mathrm{Cu}$, and $\mathrm{Zn}$, which were related with the antioxidant enzymes, in rats with glucose intolerance and obesity (Table 4B).

Exercise was reported to increase hepatic oxidative stress which, in turn, leaded to upregulate the antioxidant enzymes. Kaptanoğlu et $a l .{ }^{(38)}$ reported that in rats, $30 \mathrm{~min}$ of swimming significantly increased hepatic Fe level and significantly decreased splenic Fe level. Therefore, exercise may alter organ Fe distribution. Here, exercise increased hepatic Fe level and decreased blood, renal, and pancreatic Fe levels. These findings corroborated those of previous reports. Because $\mathrm{Fe}$ is a catalase cofactor, the observed increases in hepatic Fe level induced by exercise may be explained by an increase in active oxygen production, inflammation, or liver disease.

The measured hepatic and renal $\mathrm{O}_{2}{ }^{-}$levels disclosed that exercise increases oxygen stress (Fig. 5). Acute exercise increases active oxygen production such as $\mathrm{O}_{2}^{--}$and may enhance oxidative damage and inflammation. Relative to non-exercised healthy rats, exercised healthy rats showed significant increments in renal oxygen stress levels. On the other hand, there was negligible difference between the exercised- and non-exercised rats with glucose intolerance and obesity in terms of renal oxygen stress (Fig. 5B).

Hepatic selenoprotein $\mathrm{P}$ is a secretory protein known as a hepatokine. It participates in redox reactions in vivo since it contains a large amount of the antioxidant trace element Se in the body, ${ }^{(39)}$ and thus protects cells and organs against oxidative stress. On the other hand, when its antioxidant activity is excessive through the overexpression and secretion, it may cause diabetes or exercise intolerance. ${ }^{(17,18)}$ However, it is unclear whether exercise affects hepatic selenoprotein $\mathrm{P}$ expression. In an earlier study on professional athletes, the Se demand increased after exercise. ${ }^{(40)}$ Then, the increase in selenoprotein $\mathrm{P}$ may have been a response to exercise-induced oxidative stress. The present study suggested that exercise significantly upregulated selenoprotein $\mathrm{P}$ in both dietary groups and much remarkably in healthy rats (Fig. 6). Unlike the normal diet groups, exercise did not upregulate markedly selenoprotein $\mathrm{P}$ in the HF groups (Fig. 6). Additionally, exercise decreased plasma insulin in both diet groups (Fig. 2). Because insulin may downregulate selenoprotein $\mathrm{P},{ }^{(17)}$ exercise may have upregulated selenoprotein $\mathrm{P}$ in the normal diet groups by reducing insulin levels. However, this effect might have been cancelled in the HF diet group as a result of glucose intolerance. We also found no significant differences among all treatment groups in terms of hepatic GPx expression (Supplemental Fig. ${ }^{*}$ ). Previous studies reported that exercise upregulated hepatic GPx, however, the exercise did not upregulate hepatic GPx especially in the HF diet group of the present study. In future research, skeletal muscle GPx expression should be more evaluated to determine its relationship to exercise.

In conclusion, the salutary effects of exercise were substantially more pronounced in healthy rats than in those with glucose intolerance and obesity induced by high-fructose diet. Exercise for health has dramatically different effects on either healthy or diseased individuals. Therefore, exercise conditions and regimens must be adapted to patient health states in advance before starting exercise training intended to prevent or treat lifestyle-related diseases.

\section{Acknowledgments}

The authors thank the members of Kobe Women's University, Kyoto Pharmaceutical University, and CycloChem Bio Co. Ltd. for their assistance with the analytical techniques.

\section{Conflict of Interest}

$\mathrm{KC}$ is an employee of CycloChem Bio Co. Ltd. KT is representative director of CycloChem Bio Co. Ltd.

\section{References}

1 The Japan Diabetes Society. Treatment Guide for Diabetes 2016-2017. Tokyo: Bunkodo Co., Ltd., 2016; 26 (in Japanese).

2 The Japan Diabetes Society. Training Guidebook for Board Certified Diabetologists. Tokyo: Shindan To Chiryo Sha, Inc., 2017; 160-162 (in Japanese).

3 Boulé NG, Kenny GP, Haddad E, Wells GA, Sigal RJ. Meta-analysis of the effect of structured exercise training on cardiorespiratory fitness in type 2 diabetes mellitus. Diabetologia 2003; 46: 1071-1081.

4 Bouchard C, Rankinen T, Timmons JA. Genomics and genetics in the biology of adaptation to exercise. Compr Physiol 2011; 1: 1603-1648.

5 Stephens NA, Sparks LM. Resistance to the beneficial effects of exercise in type 2 diabetes: are some individuals programmed to fail? J Clin Endocrinol Metab 2015; 100: 43-52.

6 Cauza E, Hanusch-Enserer U, Strasser B, et al. The relative benefits of endurance and strength training on the metabolic factors and muscle function of people with type 2 diabetes mellitus. Arch Phys Med Rehabil 2005; 86: $1527-1533$

7 Cuff DJ, Meneilly GS, Martin A, Ignaszewski A, Tildesley HD, Frohlich JJ. Effective exercise modality to reduce insulin resistance in women with type 2 diabetes. Diabetes Care 2003; 26: 2977-2982.

8 Hayashi T, Hirshman MF, Kurth EJ, Winder WW, Goodyear LJ. Evidence for 5'AMP-activated protein kinase mediation of the effect of muscle contraction on glucose transport. Diabetes 1998; 47: 1369-1373.

9 Hickey MS, Carey JO, Azevedo JL, et al. Skeletal muscle fiber composition is related to adiposity and in vitro glucose transport rate in humans. Am J Physiol 1995; 268 (3 Pt 1): E453-E457.

10 Kim TH, Hwang HJ, Kim SH. Relationship between serum ferritin levels and sarcopenia in Korean females aged 60 years and older using the fourth Korea National Health and Nutrition Examination Survey (KNHANES IV-2, 3), 2008-2009. PLoS One 2014; 9: e90105.

11 Kokubo Y, Kawano Y, Mori K, Hasegawa Y, Mekata Y, Ishizaki S. Relationship between iron status and daily protein intakes in female collegiate rhythmic gymnasts. J Phys Fitness Sports Med 2010; 59: 475-484.

12 Taguchi M, Higuchi M. For Physical Education, Sports and Health Sciences. 
Tokyo: Ichimura Publishing House, 2014; 132-141 (in Japanese).

13 Suzuki K. A Real Look at Reactive Oxygen Species. Tokyo: NAP Ltd., 2014; 24-30 (in Japanese).

14 Somboonwong J, Traisaeng S, Saguanrungsirikul S. Moderate-intensity exercise training elevates serum and pancreatic zinc levels and pancreatic ZnT8 expression in streptozotocin-induced diabetic rats. Life Sci 2015; 139: 46-51.

15 Bicer M, Akil M, Baltaci AK, Mogulkoc R, Sivrikaya A, Akkus H. Effect of melatonin on element distribution in the liver tissue of diabetic rats subjected to forced exercise. Bratisl Lek Listy 2015; 116: 119-123.

16 Steinbrenner H, Bilgic E, Alili L, Sies H, Brenneisen P. Selenoprotein P protects endothelial cells from oxidative damage by stimulation of glutathione peroxidase expression and activity. Free Rad Res 2006; 40: 936-943.

17 Misu H, Takamura T, Takayama H, et al. A liver-derived secretory protein, selenoprotein P, causes insulin resistance. Cell Metab 2010; 12: 483-495.

18 Misu H, Takamura T, Saito Y, et al. Deficiency of the hepatokine selenoprotein $\mathrm{P}$ increases responsiveness to exercise in mice through upregulation of reactive oxygen species and AMP-activated protein kinase in muscle. Nat Med 2017; 23: 508-516.

19 The Japan Diabetes society. Evidence-based Practice Guideline for the Treatment for Diabetes in Japan 2013. Tokyo: Nankodo, 2013; 43 (in Japanese).

20 Kawanaka K, Koshinaka K, Sano A. Does high intensity intermittent exercise increase insulin sensitivity in epitrochlearis muscles of fasted rats? Desc Sport Sci 2006; 27: 23-31.

21 Shepherd RE, Gollnick PD. Oxygen uptake of rats at different work intensities. Pfluegers Arch 1976; 362: 219-222.

22 Stanhope KL, Schwarz JM, Keim NL, et al. Consuming fructose-sweetened, not glucose-sweetened, beverages increases visceral adiposity and lipids and decreases insulin sensitivity in overweight/obese humans. J Clin Invest 2009; 119: $1322-1334$.

23 Ueda S, Yoshikawa Y, Katsura Y, Usui T, Nakao H, Fujimoto S. Changes in gut hormone levels and negative energy balance during aerobic exercise in obese young males. J Endocrinol 2009; 201: 151-159.

24 Contarteze RV, Manchado F de B, Gobatto CA, De Mello MA. Stress biomarkers in rats submitted to swimming and treadmill running exercises. Comp Biochem Physiol A Mol Integr Phisiol 2008; 151: 415-422.

25 Winder WW, Holmes BF, Rubink DS, Jensen EB, Chen M, Holloszy JO. Activation of AMP-activated protein kinase increases mitochondrial enzymes in skeletal muscle. J Appl Physiol (1985) 2000; 88: 2219-2226.

26 Maeda K, Shimomura I. Obesity and adipocytokine. Nihon Naika Gakkai
Zasshi 2011; 100: 911-916.

27 Bradley RL, Jeon JY, Liu FF, Maratos-Flier E. Voluntary exercise improves insulin sensitivity and adipose tissue inflammation in diet-induced obese mice. Am J Physiol Endocrinol Metab 2008; 295: E586-E594.

28 Baker SK, McCullagh KJA, Bonen A. Training intensity-dependent and tissue-specific increases in lactate uptake and MCT-1 in heart and muscle. $J$ Appl Physiol 1998; 84: 987-994.

29 Enoki T, Yoshida Y, Hatta H, Bonen A. Exercise training alleviates MCT1 and MCT4 reductions in heart and skeletal muscles of STZ-induced diabetic rats. J Appl Physiol (1985) 2003; 94: 2433-2438.

30 Merrill GF, Kurth EJ, Hardie DG, Winder WW. AICA riboside increases AMP-activated protein kinase, fatty acid oxidation, and glucose uptake in rat muscle. Am J Physiol 1997; 273: E1107-E1112.

31 Bergström J, Hermansen L, Hultman E, Saltin B. Diet, muscle glycogen and physical performance. Acta Physiol Scand 1967; 71: 140-150.

32 Eshima H, Tamura Y, Kakehi S, et al. Dysfunction of muscle contraction with impaired intracellular $\mathrm{Ca}^{2+}$ handling in skeletal muscle and the effect of exercise training in male $d b / d b$ mice. J Appl Physiol (1985) 2019; 126: 170182.

33 Dudley GA, Abraham WM, Terjung RL. Influence of exercise intensity and duration on biochemical adaptations in skeletal muscle. J Appl Physiol Respir Environ Exerc Physiol 1982; 53: 844-850.

34 Greiwe JS, Hickner RC, Hansen PA, Racette SB, Chen MM, Holloszy JO. Effect of endurance exercise training on muscle glycogen accumulation in humans. J Appl Physiol (1985) 1999; 87: 222-226.

35 Pham PC, Pham PM, Pham SV, Miller JM, Pham PT. Hypomagnesemia in patients with type 2 diabetes. Clin J Am Soc Nephrol 2007; 2: 366-373.

36 Wang H, Kruszewski A, Brautigan DL. Cellular chromium enhances activation of insulin receptor kinase. Biochemistry 2005; 44: 8167-8175.

37 Oh-ishi S. Exercise and oxidative stress. IRYO 2015; 69: 317-324 (in Japanese).

38 Kaptanoğlu B, Turgut G, Genç O, et al. Effects of acute exercise on the levels of iron, magnesium, and uric acid on liver and spleen tissue. Biol Trace Elem Res 2003; 91: 173-178.

39 Koyama H, Abdulah R, Yamazaki C. The role of selenium for cancer chemoprevention and anti-aging. Biomed Res Trace Elements 2009; 20: 19 29 (in Japanese).

40 Maynar M, Llerena F, Bartolomé I, et al. Seric concentrations of copper, chromium, manganesum, nickel and selenium in aerobic, anaerobic and mixed professional sportsmen. J Int Soc Sports Nutr 2018; 15: 8. 